\title{
The Development of a Diagnosis Indicator-Based Assessment Tool and Its Application to Rural Settlements in the Region Montes de Maria in Colombia
}

\author{
Rabya Yawar-Mehmood*, Laura Garcia Rios, Cathrin Zengerling, Udo Dietrich
}

REAP Research Group (Resource Efficiency in Architecture and Planning), Hafen City University Hamburg, Hamburg 20457, Germany

Corresponding Author Email: rabya.yawar@ gmail.com

https://doi.org/10.18280/ijsdp.150201

Received: 29 April 2019

Accepted: 24 May 2019

Keywords:
agricultural households, biodiversity,
environmental impact, household-
centered surveys, indicator-based
assessment tools, post-conflict Colombia,
resource efficiency, sustainable rural
development

\section{Keywords:}

agricultural households, biodiversity, centered surveys, indicator-based development

\begin{abstract}
One of the most affected regions in Colombia in terms of social conflict, deforestation and loss of biodiversity is the region called Montes de Maria. In view of the current land restitution plan the trend of the environmental degradation is most likely to increase due to a higher demand of natural resources caused by the returning population that was displaced during the conflict. With the objective to develop a simple and quick method to diagnose the inefficient and environmentally unsustainable consumption and management of resources for domestic and agricultural purposes from households in that region, the most inclusive method is approached supported by a literature review. As a result, the indicator-based assessment tool pro.eraa was developed with the help of the reference certification tool Green Villages by IGBC of India, the Technical Advice by the One Planet Development of Wales, the local NBA as guidelines and the SDI's of the SDGs. Pro.eraa consists of a total of 51 indicators in the four resource themes: water, energy, waste and activity. The fourth resource "Activity" was necessary to be added during the process due to the agricultural context of the region. Pro.eraa was validated and pre-tested on two sites (Huamanga and Chalan) in Montes de Maria. The tool serves as a decision-aid tool to support the selection of tailored and effective interventions that benefits efficiency and environmental sustainability in regard to the human well-being of the rural population as well as the local biodiversity. Apart from the design and validation process, the work includes a showcase application and evaluation of a site and instructions for implementation. During the literature review, it was particularly noted that the current state of the art literature lacks adequate indicator-based assessment or certification tools that lay the focus on sustainable rural development.
\end{abstract}

\section{INTRODUCTION}

One of the most affected regions in Colombia in terms of both guerilla activity and deforestation is the region called Montes de Maria, an isolated group of small mountains near the northern coast of the Colombian Caribbean. In this region over $90 \%$ of the original dry forest has been lost [1]. As indicated, moreover, Montes de María is one of the regions with the greatest impact in violence and displacement due to the armed conflict. Under the Marke-D project, the Colombian foundation Fondo Patrimonio Natural (hereafter: Patrimonio) aims to re-enhance the biodiversity through the establishment of a green corridor. For this, multiple macro projects for farmers shall be allocated in the Montes de Maria region. This requires a baseline data acquisition of the existing situation of resources of households regarding water, energy, waste and activity. To facilitate this, a tool is developed and validated on site in the framework of the thesis, which will enable Patrimonio to increase the understanding of the resources' demand, its management and efficiency for domestic and nondomestic (such as agricultural) activities. The allocated activity task for the HafenCity University is to 'carry out a diagnosis of the efficiency performance of the resources of rural households' (translated from Spanish from the official project documents). The tool diagnoses the problem of the investigated areas to allow a customized solution. Ideally, the tool shall serve any project as a decision-aid tool that aims to identify the resource efficiency of households in settlements.

In consensus with Patrimonio, the brief for the study implied the tool to provide the following criteria:

- Be able to quickly collect and compare baseline data

- Be able to highlight areas of good or bad performance, preferably on site

- Ability to monitor by comparing before and after values of the assessed area

- Allow comparison of performances with other areas

- Be easily applicable, replicable and capable of being monitored in house

- Be applicable across a range of spatial levels - from the smallest, most scattered hamlet to larger market towns

- Invest as little as possible resources such as time, capital and staff

- Consider local climatic conditions and settings

Therefore, the specific objective of the thesis is to develop a simple and quick method to diagnose the inefficient and unsustainable consumption and management of resources from households in Montes de Maria in form of a decision-aid 
tool in order to enable the implementation of a tailored and effective solution that provide human well-being and biodiversity benefits.

In each of the four resources water, energy, waste and activity, targets will be defined in the process of the tool design that serve the specific objective.

This paper is based on a collaborative thesis work by two students of the Master program Resource Efficiency in Architecture and Planning at the HafenCity University in Hamburg, Germany. In cooperation with Fondo Patrimonio Natural, a four-weeks field study was carried out in March 2018 to validate and refine the pilot tool by collecting data in two suitable sites in Colombia.

\section{METHODS OF DESIGN AND VALIDATION}

\subsection{Research question}

In regard to the research objectives, the present study intends to evaluate:

What is the most inclusive method to measure and assess the resource efficiency performance of agricultural households in Montes de Maria in Colombia? And what approach shall be followed to develop this assessment method for resource efficiency?

In addition, the study also intends to obtain significant conclusions regarding the following aspects:

- When, where and how can this tool be applied? What are the benefits and limitations of this tool?

- Which aspects shall be beared in mind in the development of an assessment tool for resource efficiency in the rural context?

\subsection{Study design}

The design of this practical oriented study basically consists of four major steps: the design of the tool, its validation on site, the show-case study and implementation guidelines.

Step 1 Tool design: In alignment with the project needs and together with Patrimonio, the core resource sectors or broad topics of concern for the tool is determined. A literature review provides an overview of the research status quo of similar tools for each sector and/or existing tools that address all resource sectors in one. A research framework is set for this with context related characteristics to identify the most suitable reference tools. With the support of reference tools the elements of the tool are designed chronologically step by step. The design elements consist of the following: objectives, categories, criteria, indicators, benchmarking, weighting and display of results. It is decided to develop the tool as an MS Excel-based tool for user-friendly handling and to be easily applicable and replicable.

Step 2 Tool validation: The primary purpose of the field study is to 1) validate the data collection method of the indicators, 2) train the local surveyors to apply the data collection methods and 3) collect data from households as input parameters for a show case study (for Step 3). As a secondary intent, the field study also serves to collect experience values on the implementation of such a tool regarding required time, cost, staff and procedure (for Step 4).

Step 3 Tool analysis: The collected data in the previous part serves as input parameters to demonstrate a case study on the application of the tool. A step-by-step explanation from data collection up to the evaluation of results is provided including the diagnosis of the resource efficiency performance of the second site.

Step 4 Implementation guidelines: Once the tool is "readyto-use", the best method to integrate and implement is defined. Questions, such as how, by whom and to what constraints the tool is applicable are discussed in this part. A user-friendly instruction on how to use the Excel tool describes the application for the tool. Principles for intervention serves as a guideline for the subsequent step after the diagnosis result of the tool.

\subsection{Tool design}

The outcome of the literature research in the tool design identified indicator-based assessment tools to be the most inclusive method to measure and assess the resource efficiency performance and meet this research specific objectives. The assessment scale is selected to be "Neighborhood scale" as it comes the closest to a rural settlement. Even though both are not equal, however a neighbourhood consists of structures that are independent from the greater urban area but is yet dependent of it, just like a rural settlement. This allows a certain flexibility in applying the tool to local communities regardless of their municipal affiliation. In cooperation with Patrimonio, the main field of activities was specified to be the resources Water, Energy, Waste and Activity. At this point the fourth resource by the term "Activity" is added that refers to the land-based activities of residents either for subsistence or economic purpose. This resource holds Patrimonio's longterm vision for rural areas, thus it also contains the possibility to measure fields of action, such as awareness activities and innovative activities. Thus, the resource "Activity" comprises: Subsistence and Enterprise, as well as Awareness and Innovation.

A framework, consisting of five factors that derive from characteristics relevant to the project (High biodiversity and/or natural conservation emphasis, Similar climate zone /belt region, Rural context, Colombian context, Developing country context), was applied to scan a broad range of neighborhood scale tools in a literature review from a wide array of sources.

This framework was applied to review Environmental Indicator-Based Tools, Sustainability Indicator-Based Tools and Green Building Certification System Tools (Neighborhood Scale). Due to the limited scope of this study it was decided to only focus on the tools which are fully developed and their manuals are accessible (publicly available). The highest number of compatible criteria was identified to be the tool IGBC Green Villages India. Further materials beyond tools were analysed that could be useful in the development process of the diagnosis tool. Materials can be manuals, guidelines, standards, reports etc. One document that was found in this context with a high relevance is a planning document for sustainable rural communities published by the Welsh Government. It is a Technical Advice Note named One Planet Development Guide (OPD) "that provides advice on areas including sustainable rural communities and economies, rural affordable housing, rural enterprise dwellings, one planet developments, sustainable rural services and sustainable agriculture" [2]. On the national level in Colombia the Necesidades básicas insatisfechas (NBI) or Unsatisfied Basic Needs is a direct method used by the National Administrative Department of Statistics to identify critical deficiencies in a population and characterize poverty. 
It uses indicators directly related to four basic need areas of people (housing, health services, basic education and minimum income)

The Sustainable Development Indicators (SDI) serve the monitoring of the UN Sustainable Development Goals. The relevant goals for us would then be SDG Goal 6 for Water, 7 for Energy and 12 for Waste. Thus, the design of the tool was supported by four eligible identified reference materials:

(1) Necesidades básicas insatisfechas (NBI) [3],

(2) IGBC Green Village Rating Tool (India) [4],

(3) One Planet Development Guide (UK) [2] and the

(4) Sustainable Development Indicators (Global) [5].

The research for reference tools further identified a research gap in the area sustainability assessment tool for the rural context. Much of the focus in today's literature and practice is laid on the sustainable development of cities. The indicatorassessment tool was designed chronologically level-by level [6]. The reference tools served in the creation of up to the first four levels of the tool according to the basic Basic structure of indicator-based sustainability assessment tools by Ebert, Eßig, Hauser, 2011 [7], which consists of the elements "objectives", "categories", "criteria" and "indicators".

1 st level "Objectives": If we elaborate the main goals and project them on the resources, this would lead us to the following interpretations:

The resource efficient local community is one which offers access to adequate water, sanitation, clean energy, a waste collection system (for waste which cannot be assimilated on the site) and is leading to economic prosperity and enhanced quality of life, in a way that is environmentally sustainable. For water and energy this means that the majority of water and energy needs is met from sustainable water sources and renewable energy sources on site. The minimisation of energy consumption, water consumption and waste generation are a prerequisite to achieve a low environmental impact. Potential reuse and recycle opportunities in regard to water and waste are utilized to the maximum. Wastewater is treated and waste that is either non-biodegradable or hazardous waste is assimilated or produced in very small amounts and disposed off properly. For the resource activity, the site produces enough food to cover the food needs of the residents and generates enough income to pay for the basic requirements of all the residents on the site which the site is unable to provide directly (such as clothes, travel, IT/communications and the food needs that are not covered by self grown). The farmers have access to farm assets, produce diverse agriculture products and contribute to the promotion of the local economy (connection to close urban market). Sustainable farming techniques are widely spread and innovative experiences constantly exchanged in workshops and trainings. Most farmers are involved in alternative income sources and live in houses that consist of locally available construction materials. Awareness campaigns are held regularly on, nature conservation measures, the principles of the green township and on innovative measures that demonstrate reduced environmental impacts. The objectives are a result of a review of the reference tools and after consultation with Patrimonio.

2nd level "Categories" or "Resources": The categories are equal to the sectors, thus to the four resources water, energy, waste and activity.

Additional level "Areas": In our specific rural context of subsistence farming a substantial proportion of the water and energy demand are formed by non-domestic activities. The generated agricultural waste may even be larger than the household waste. Those resources may come from the same supply chain and run into the same disposal chain. This cannot be neglected in the assessment of the site considering our overall objective to achieve a resource efficiency in the site. In order to distinguish this, the first step is to divide each of the first three resources into the areas domestic and non-domestic. This means that these resources have a second structural level, which is not typical in other assessment tools.

Additional level "Components": To ensure coverage of the entire life cycle of a resource we introduce components before defining the criteria. These components are Access, Supply, Demand and Management.

5th level "Criteria": With support of the reference tools the categories are subdivided into criteria and sorted according to the components.

6th level "Indicators": On the last level are factors which makes the tool tangible to "measure" resource efficiency which is described with the support of indicators. Indicators assess neighbourhoods in terms of their quality (descriptive) or quantity (by numbers, units or metered values) [7].

The basic structure of the tool design for each resource with all levels is displayed in Figure 1. With the analysis of the reference materials each case individual indicators are tailored specifically to the characteristics of the criterion. A total of 51 indicators were designed. Table 1 shows exemplary the final structure for the resource "Energy" indicating all levels.

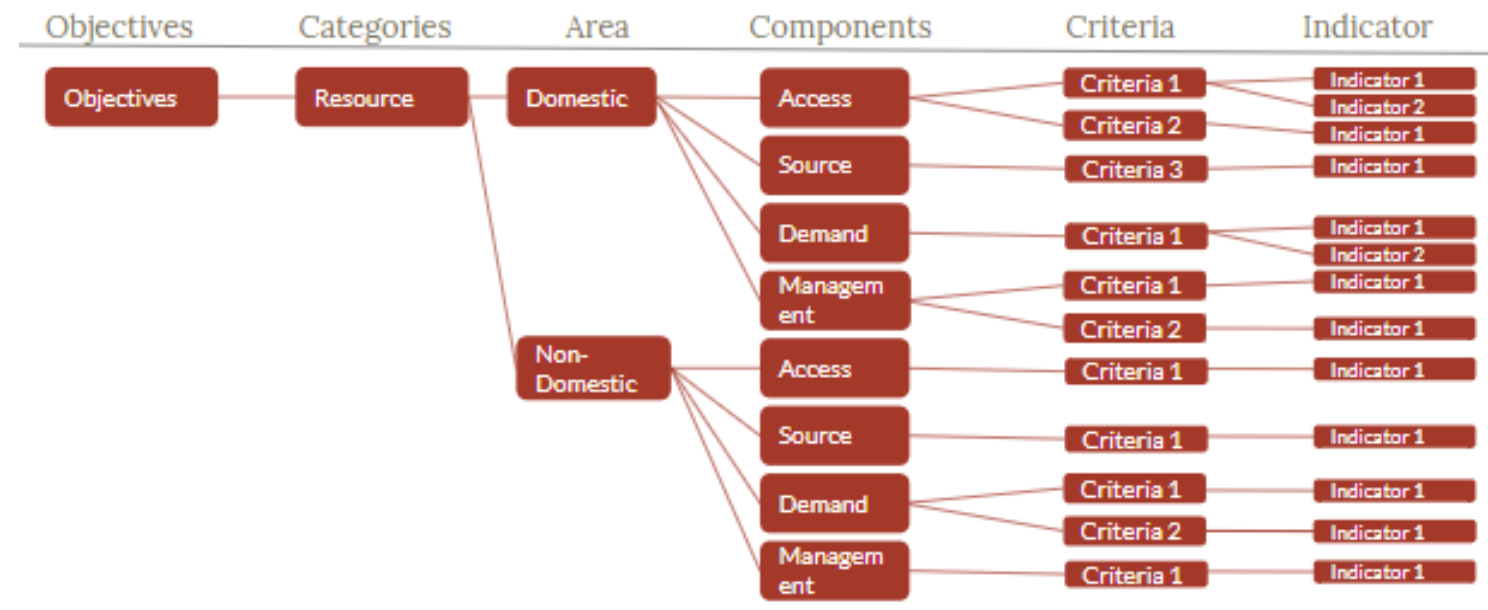

Figure 1. Overview of basic structure of the tool design with modules on 6 levels 
To collect the information required for each indicator, the following data collection methods were applied:

(1) Information collected through Households interviews by Questionnaires

(2) Information collected through interviewing the local authority by a prepared Questionnaire

(3) Information collected through own observations
(4) Data collected from secondary sources, such as Online Data

(5) Optionally: Information collected in a Workshop with the local community for problem prioritization

The latter ascribes from Sharifi's critique that emphasizes the lack of community involvement in sustainability assessment tools [8].

Table 1. Master structure of the tool pro.eraa for the resource "Energy"

\begin{tabular}{|c|c|c|}
\hline Component & Criteria & Indicator \\
\hline Access & Access to affordable, reliable and modern energy services & Proportion of households with access to electricity \\
\hline Supply & $\begin{array}{l}\text { Encourage renewable energy generation/increase substantially the } \\
\text { share of renewable energy }\end{array}$ & $\begin{array}{l}\text { Proportion of households with renewable energy use } \\
\text { for domestic consumption }\end{array}$ \\
\hline Demand & Minimisation of energy demand & $\begin{array}{c}\text { Daily per capita energy consumption in } \mathrm{Kwh} / \mathrm{Kep} \text { over } \\
\text { time }\end{array}$ \\
\hline \multirow[t]{3}{*}{ Management } & Renewably powered water pumping (if applicable) & $\begin{array}{c}\text { Availability of water pumping that is run by renewable } \\
\text { energy }\end{array}$ \\
\hline & $\begin{array}{l}\text { Use Solar Water Heating Systems for household water } \\
\text { requirement to reduce use of fuelwood and deforestation }\end{array}$ & $\begin{array}{l}\text { Proportion of households with application of Solar } \\
\text { Water Heating Systems for hot water demand }\end{array}$ \\
\hline & $\begin{array}{l}\text { The use of resources efficiently to reduce use of fuelwood and } \\
\text { deforestation }\end{array}$ & $\begin{array}{l}\text { Proportion of households with dependence on clean } \\
\text { fossils for cooking and light }\end{array}$ \\
\hline Supply & Cover of all non-domestic activities by renewable energy & $\begin{array}{l}\text { Proportion of households that use renewable energy for } \\
\text { economic activities }\end{array}$ \\
\hline Demand & Minimisation of energy demand for economic activities & $\begin{array}{l}\text { Monthly per capita energy consumption in Kwh for } \\
\text { non-domestic use }\end{array}$ \\
\hline
\end{tabular}

1) Methodology of data collection

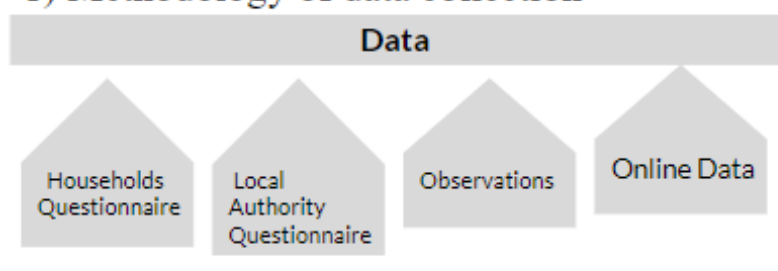

3) Presentation of results

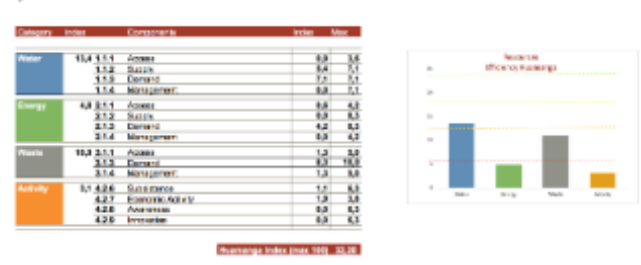

\section{2) Data input into excel tool}
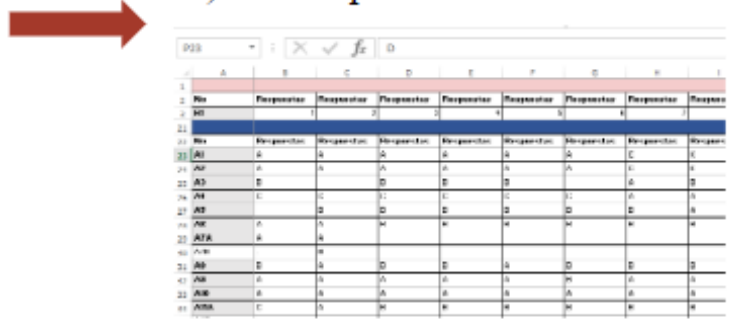

Figure 2. Overview of tool application: After the data is collected (1), it shall be inserted into the Excel Calculator (2) which will automatically illustrate the results (3)

It is possible for a large number of indicators to be collected directly from the household owners. For this, the indicators are transformed directly into questions adopted and adapted from harmonized questions by lead agencies $[9,10]$. The design process and the applied reference tools is explained in more detail in a sheet for each indicator providing information on benchmarking, Weighting and Data Collection Method. In order to reduce the theoretical controversial subjectivity of weighting $[11,12]$ and also due to the nature of our tool, we decided to weight the components evenly.

Each of the four resources are assigned the same amount of weightage, which is represented by a unitless number of 25 . This number is divided by the number of components of each resource, which results in the weightage factor assigned to each component. Furthermore the result from the previews divisions number is divided by the number of criteria of each component, which results in the weightage factor assigned to each criteria. If one one criteria has more than one indicator assigned the weighting of the criteria will be divided for the number of indicator assigned to the criteria.

A majority of the indicators measure the proportion of households that possess a condition defined by the indicator. This is divided by the total number of households and multiplied with the weighting factor as per following equation:

$$
\begin{aligned}
& \left(\frac{\text { number of households with indicator } x}{\text { total number of households }}\right) x \text { (weighting factor) } \\
& =\text { result value }[\%]
\end{aligned}
$$


The developed tool is incorporated into an Excel file, in which the collected data can be inserted in order to view the diagnostic results of the investigated site (Figure 2).

\subsection{Tool validation}

The following five key stakeholders from the society, government and NGO were identified that are active in Montes de Maria and relevant for the pro.eraa tool:

- Fondo Patrimonio Natural, as the holder of pro.eraa and the main implementer.

- Farmers of the region Montes de Maria as the main party concerned for the implementation and the direct implications of pro.eraa. Their involvement is crucial for the functionality of pro.eraa.

- Local interviewers that carry out interviews in households. They originate from the region and have a relation to the area and the inhabitants. As Patrimonio has worked at the area before our field study, they facilitated us two interviewers called promoters (in Spanish: Promotores). The promoters were already empowered to encourage sustainable practices and protect the environment by Patrimonio in previous projects.

- Local leaders as the mediator between the local interviewers and the farmers.

- Mayor or the local executive officer in municipalities

Two sites with different geographically and demographically characteristics are visited in order to prove the applicability of the tool regardless of the context of the area. These two sites are Chalan and Huamanga. The main method to collect the data for the indicators are household-centered surveys, which have been developed and pre-tested on two sites in Montes de Maria. This practical exercise enabled the optimization of the tool and adjusted it to the understanding of the regional specific context. Survey of the local authority could not be pre-tested due to inaccessibility and a workshop in this stage of the tool design was not feasible. It is recommended to have a second round of tool validation with a more consensus-based and the involvement of multi-actors stakeholders. Local surveyors are from the region and part of the project through Patrimonio. In order to be able to collect data from various sites, they are instructed by us during the tool validation process in Montes de Maria on how to apply the tool and any unclear technical terms were explained.

\subsection{Tool analysis}

The data collected in the second site, a remote village called Huamanga, was utilized to illustrate as an example on how to use the Excel Calculator and interpret the diagnostic results. For this purpose, a total of 20 households questionnaires, which is equivalent to $18 \%$ of the total households were collected and evaluated. The local authority survey could not be applied due to inavailability of the mayor in Carmen de Bolivar. Due to the distances and lack of time and means, the feasibility of conducting a workshop is considered low and would make it difficult to replicate later by users of the tool, which goes against the research objective of a simple and quick method.

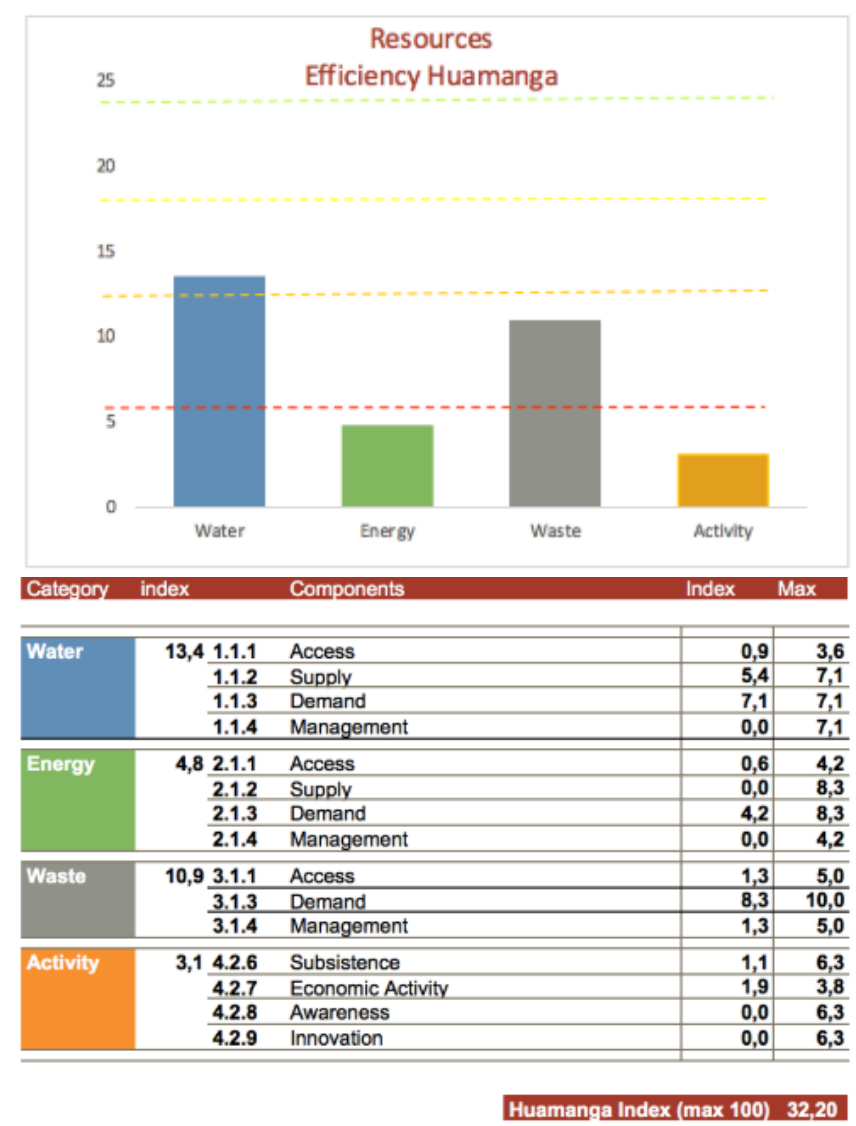

Figure 3. Index results of the tool application for the case study Huamanga

Table 2. Overview assessment sheet per criteria for Energy for the case study Huamanga

\begin{tabular}{|c|c|c|c|c|}
\hline Component & Criteria & $\begin{array}{c}\text { Max } \\
\text { Results }\end{array}$ & $\begin{array}{l}\text { Huamanga } \\
\text { Results }\end{array}$ & $\%$ \\
\hline Energy & & 25,0 & 6,7 & $27 \%$ \\
\hline \multicolumn{5}{|c|}{ Domestic } \\
\hline Access & Access to energy services & 4,2 & 2,5 & $60 \%$ \\
\hline Supply & $\begin{array}{l}\text { Encourage renewable energy generation/increase substantially the share of } \\
\text { renewable energy }\end{array}$ & 4,2 & 0,0 & $0 \%$ \\
\hline Demand & Minimisation of energy demand & 4,2 & 4,2 & $100 \%$ \\
\hline \multirow{2}{*}{ Management } & Renewably powered water pumping (if applicable) & 2,1 & 0 & $0 \%$ \\
\hline & The use of resources efficiently to reduce use of fuelwood and deforestation & 2,1 & 0 & $0 \%$ \\
\hline \multicolumn{5}{|c|}{ Non-Domestic } \\
\hline Supply & Cover of all non-domestic activities by renewable energy & 4,2 & 0 & $0 \%$ \\
\hline Demand & Minimisation of energy demand for economic activities & 4,2 & 0 & $0 \%$ \\
\hline
\end{tabular}


After the data has been inserted into the Excel Calculator, the results could be read: The overall index of resource efficiency in Huamanga indicates a value of 32,20 out of 100 (Figure 3). The efficiency of all four resources is not high, however water efficiency and waste efficiency perform better than energy and activity. A closer look at the first three resources shows the highest value in the component "Demand", which indicates a low consumption of water and energy and a low generation of waste. Regarding the component "Management" all the first three resources perform very poor. Less than half of the households have access to water and the situation for access to energy is only slightly better. The households that have access however, have no sustainable energy sources, which indicates the component "Supply" in energy. Resource 'Activity' reads that subsistence as well as economic activity are critical. There is no awareness regarding environmental protection and no innovation regarding sustainable practices.

The next Excel sheet illustrates the results per criteria for each resource. Table 2 exemplary presents the results for the resource "Energy", which scores an overall value of $27 \%$. Per component, the most critical criteria (index $\leq 25 \%$ ) can be derived from this assessment sheet. For further information of each criteria, the next Excel sheet "Results per indicator" can provide revealing insight on request.

With the support of this show-case study a detailed application instruction of the tool is elaborated in the thesis work.

\subsection{Implementation guidelines}

Based on the experiences gained during the pre-test, this part develops guide values for the estimation of minimum required time, costs and staff network in implementation of the tool. These guides show that a procedure with a minimum human capital of four person is required to apply a diagnosis analysis of the tool with a project manager (PM) in the head quarter, a field worker on site, an interviewer and a local community leader of the targeted site. Among this four, it is just the project manager, using the Excel Calculator for the diagnosis, while the others are involved in the data collection process. As the use of the Excel Calculator requires a basic understanding of resource efficiency, it is difficult to run on its own and on site. This means, the PM sends the diagnosis results to the local authority and local leader (Figure 4).

With this procedure, the PM successively collects data from sites in the region Montes de Maria. This enables the PM to have a good overview on macro and regional scale and shall support the decision-making process on the selection of intervention projects.

Further, in the thesis work this part also lays out a Monitoring \& Evaluation guideline, an approach to select interventions as well as examples of interventions.

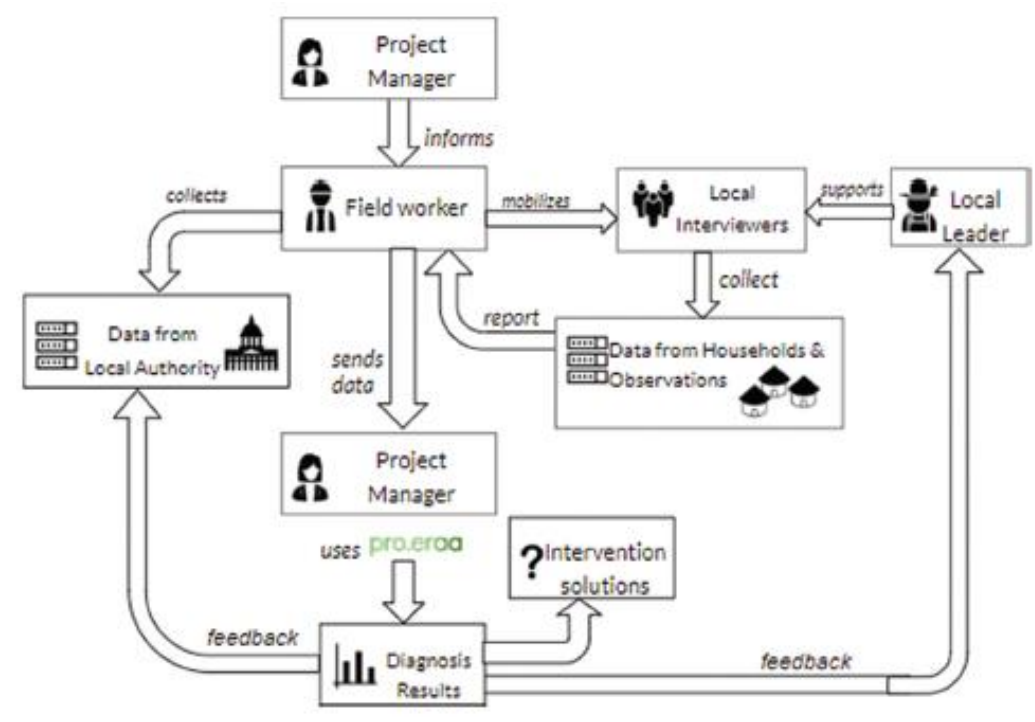

Figure 4. Required operational procedure to implement pro.eraa

\section{RESULTS}

Based on applied research the final product of this practical oriented study is an indicator based assessment tool for resource efficiency in agricultural households in Montes de Maria.

The tool analyses the state of the art of the access, supply, demand and management of the resources water, energy, waste and activity. It consists of 16 criteria with 21 indicators for water, 7 criteria with 8 indicators for energy, 10 criteria with 11 indicators for waste and 10 criteria with 11 indicators for activity. In retrospect, the research reviewed that designing and implementing an appropriate indicator-based assessment tool for resource efficiency can be challenging and requires the consideration of the following aspects:

- Reference tools can provide a helpful guidance on the design of assessment tools. A research framework can help identify appropriate reference tools.

- Benchmarking indicators is the most challenging component of the design process. It requires an individual research for each indicator and some indicators are designed to establish a benchmarking with every new data input.

- Developing questionnaire requires a design process of its own. Sufficient time shall be dedicated for the design of the questionnaires with research for appropriate model questionnaires.

- The most important criterion for designing the 
indicators is the accessibility and availability of data.

- Coming from a locally known institution like Patrimonio was massively helpful during the field trip in terms of orientation, existing contacts to the local community leaders and the provision of suitable interviewers. This granted us credibility towards the household owners and their willingness to participate in the survey.

- Planning a workshop is a complex matter that requires time, costs and experienced staff and an announcement sufficient time ahead.

- The quality of the data obtained depends on the proper design of the survey and a good knowledge transfer and training of the interviewers.

- The involvement of the local authority should not be taken for granted and need to be strategically planned. However, the tool has to be designed to function also in cases of inaccessibility of the local authority.

- To run a show case study is not only demonstrative for the future tool users but also helps to mirror your own work and results.

- A new tool comes with expectations and interests from different stakeholders. The first step is to establish a consensus of the purpose and objectives of the tool.

- The idea of a fully automatic tool is unrealistic. A certain amount of structure and means are necessary, and a basic understanding of resource efficiency for the interviewers is essential.

- The interdisciplinary nature of the tool caused for some indicators an unclear assignment to one resource.

\section{FINAL DISCUSSION}

The methodological approach determined the most inclusive method to measure and assess the resource efficiency performance of agricultural households in Montes de Maria in Colombia to be an indicator-based assessment tool. This tool was developed in a quantitative research based on a literature review from which guiding reference materials were derived. A negative finding in this phase was the research gap of sustainability assessment methods for rural areas.

The tool serves the main purpose to produce rapid findings at relatively low effort while enabling the monitoring of locallevel projects. Apart from the operational limitation laid out in section 2.6, the tool can also only be applied in the agricultural context. However, it is geographically flexible and can be split by sector/resource.

Indicator-based assessment is in essence an approach to convert qualitative information into numerical data in order to evaluate the state-of-the-art and make it comparable. the quantification of information is in every case related to a loss of qualitative or local-specific information. The key issues in the process of the tool development were to find the balance between the amount of quantification of local-specific information and the requirement to have a faster and a more comparable diagnosis from which the approach of a community-based participation also suffers from. Ways on how to include the concerned local communities must be factored in during the selection of intervention phase. Another key issue is the process of weighting assignment that is vulnerable to ambiguity due to its subjective nature. Derived mainly from the intention to not prioritize neither environmental nor human indicators, our approach of assigning equal weighting factors solved this issue partially. Lastly, the data obtained states and does not explain a static condition with some exceptions that requires a manual causation, such as no energy consumption due to no access to electricity. In most cases though, it does not explain i.e. the low consumption of energy. This leads to what we have seen in the case of Huamanga: The tool does not reflect political or social situation and assesses the low consumption for electricity as positively sustainable when the household cannot afford electrical appliances. This means, the tool does not serve as a proxy for social variables.

On a large scale, sustainability indicators are a proven method for driving sustainable urban development as a progress-measurement tool or static sustainability diagnostic. This research shows that indicator-based assessment tools can very well provide simple, measurable evidence needed to create and maintain rural areas that are environmentally sustainable, promote long-term biodiversity benefits, as well as provide prosperity in regard to the well-being of their residents.

\section{ACKNOWLEDGMENT}

This work is supported by the Foundation Fondo Patrimonio Natural and is part of the Marke-D project. The Marke-D project aims to increase conservation areas and implement a sustainable management of the Tropical Dry Forest in the areas with a great biological significance in Montes de Maria. Main funds come from the program Riqueza Natural (USAID). As a strategy the non-profit foundation will implement corridors of conservation, that will be protexted areas by a network of households with agreements of conservation and sustainable practices with efficient use of the resources. The development of the tool in this work is an activity task of the Marke-D project.

\section{REFERENCES}

[1] Pizano, C., Garcia, H. (2014). El Bosque Seco Tropical en Colombia, Instituto de Investigaciones y Recursos Biológicos, Bogotá D.C, Alexander von Humboldt (IAvH). http://dx.doi.org/10.21068/B001.2015.202

[2] Land Use Consultants and the Positive Development Trust, One Planet Development. Technical Advice Note 6. Planning for Sustainable Rural Communities, https://gov.wales/docs/desh/publications/121114onepla netguideen.pdf, 2012.

[3] Feres, J.C., Mancero, X. (2001). El método de las necesidades básicas insatisfechas (NBI) y susaplicaciones en América Latina, Naciones Unidas CEPAL, División de Estadística y Proyecciones Económicas. Publicación de las Naciones Unidas.

[4] IGBC Indian Green Building Council. (2016). IGBC Green Villages. Pilot Version, Abridged Reference Guide.

[5] Report of the Inter-Agency and Expert Group on Sustainable Development Goal Indicators (E/CN.3/2016/2/Rev.1), Annex IV. (2016). Final list of proposed Sustainable Development Goal indicators.

[6] Chesson, J. (2002). Science for Decision Makers. Sustainability Indicators: Measuring Our Progress. BRS Bureau of Rural Sciences. 
[7] Ebert, T., Eßig, N., Hauser, G. (2011). Green building certification systems: Assessing sustainability International system comparison Economic impact of certifications, München: Institut für internationale Architektur-Dokumentation. p. 90. http://dx.doi.org/10.11129/detail.9783955531683

[8] Sharifi, A., Murayama, A. (2013). A critical review of seven selected neighborhood sustainability assessment tools. Environmental Impact Assessment Review, 38: 73-87. http://dx.doi.org/10.1016/j.eiar.2012.06.006

[9] UN HABITAT, Urban Inequities Survey, M A N U A L, Global Urban Observatory Monitoring and Research Division, Adapted from Demographic and Health Survey and Multiple Indicators Cluster Survey, http://mirror.unhabitat.org/downloads/docs/UrbanInequities-Survey-Manual.pdf, unknown.
[10] World Health Organization and UNICEF, Core questions on drinking-water and sanitation for household surveys, WHO Library Cataloguing-in-Publication Data, ISBN 924156326 5, ISBN 9789241563260 , NLM classification: WA 675 , https://www.who.int/water_sanitation_health/monitorin g/oms_brochure_core_questionsfinal24608.pdf, 2006.

[11] Retzlaff, R. (2009). Green buildings and building assessment systems: A new area of interest for planners. Journal of Planning Literature, 24(1): 3-21. http://dx.doi.org/10.1177/0885412209349589.

[12] Alwaer, H., Sibley, M., Lewis, J. (2008). Different stakeholder perceptions of sustainability assessment, in: Archit Sci Rev 2008 Nr. 51(1): 48-59. http://dx.doi.org/10.3763/asre.2008.5107 